Hydraulic Engineering Repository

Ein Service der Bundesanstalt für Wasserbau
Ali, Shahid; Uijttewaal, W. S. J.
Flow resistance of vegetated weir-like obstacles during high water stages

Verfügbar unter / Available at:

https://hdl.handle.net/20.500.11970/99658

Vorgeschlagene Zitierweise / Suggested citation:

Ali, Shahid; Uijttewaal, W. S. J. (2010): Flow resistance of vegetated weir-like obstacles during high water stages. In: Dittrich, Andreas; Koll, Katinka; Aberle, Jochen; Geisenhainer, Peter (Hg.): River Flow 2010. Karlsruhe: Bundesanstalt für Wasserbau. S. 293-300. 


\title{
Flow Resistance of Vegetated Weir-like Obstacles during High Water Stages
}

\author{
S.Ali \& W.S.J. Uijttewaal \\ Environmental Fluid Mechanics Section, Faculty of Civil Engineering and Geosciences, Delft University \\ of Technology, Postbox 5048,2600GA, Delft, the Netherlands;
}

\begin{abstract}
At high water stages obstacles in the flood plains of a river contribute to the flow resistance. In particular the elevated and vegetated parts are expected to play an important role. The objective of this study is to estimate and parameterize the form drag due to vegetated weir-like obstacles. An Experimental study has been carried out in the Laboratory of Environmental Fluid Mechanics of Delft University of Technology. The prototype dike and groyne have been modeled as a weir with various downstream slopes $(1: 4,1: 7,1: 15)$ and vegetation has been represented in various shapes ( such as cylinders , cones and gaze with different mesh sizes) placed on top of the crest of weir with $25 \%$ blockage area inside the vegetated region. Measurements for energy head losses were carried out for a range of discharges and downstream water levels covering submerged and subcritical flow conditions. The head loss due to submerged vegetated dikes and groynes has been modeled by an expansion loss form drag model (Energy and momentum balance principles). Expansion loss form drag models have been derived from a one- dimensional momentum conservation equation and accounts for the energy loss associated with a deceleration of the flow downstream of a sudden flow expansion. Predicted results by the expansion loss form drag model show some deviation from experimental results due to the downstream slope effects and nonuniform velocity distribution at the vegetated cross section on the crest of weir.
\end{abstract}

Keywords: Vegetated weir, Expansion loss form drag model, Flow resistance, Groyne

\section{INTRODUCTION}

For a river reach at high water stages, three different zones could be distinguished such as; main channel, groyne field and flood plain. All of these parts contribute to the flow resistance due to the different features. In the main channel, the flow resistance is mainly caused by the bed roughness and the small scale features like ripples and dunes. The flow resistance in the groyne field is caused by a combination of bed roughness and the groynes. In the flood plain there are many features such as the summer dikes, approach roads, ditches, bushes, trees and the plain gross land. Some weirlike structures such as access roads, summer dikes, groynes are also covered with vegetation and could be oriented perpendicular to the flow like plain weirs or at an angle to the flow like oblique weirs. The combination of vegetation and elevation gives rise to a high resistance to flow, so it causes flood level rise in the rivers. Hydraulic resistance of these features is difficult to estimate as there is a strong mutual interaction between the separating flow and the vegetation-induced turbulence. Computer models (1D and 2D flow models) often don't include such features and should therefore be improved with respect to representation of vegetated dike resistance. The resistance to the flow due to vegetation has been studied extensively. The same holds for simple weirs but the combined effect of submerged vegetated dikes and groynes has not yet been studied in depth. These flood plain features (summer dike, access road and spur dikes) could be schematized as a weir or as a drag generating obstacle in the flow. Many researchers investigate the weir properties; Such as Rehbock (1929) Villemonte (1947), Chow (1959), Abou-Seida and Quraishi (1976), Henderson (1966), Govida Rao and Muralidhar (1963), Swamee (1988), Lakshmana Rao (1975), Jain (2001), Chanson (1999). Yossef (2005) considered groin as an obstacles and concluded that to reduce the effect of the spur dikes on flood level, their height should be decreased. Azinfar and Kells (2009) develop a relationship for the spur dike drag coefficient. The effects of submerged and unsubmerged 
rigid and flexible vegetation on the flow has been studied by Kouwen and Unny (1973), Li and Shen (1973), Nepf (1999), Kouwen and FathiMoghadam (2000), López and García (2001), Järvelä (2004) and Baptist (2005). Objective of this study is to estimate the form drag due to vegetated weir- like obstacles. To this end, the expansion loss form drag model has been derived based on 1-D momentum conservation equation to account the energy loss caused by the decelerating flow downstream of a sudden expansion. The predicted results by a form drag model based on expansion loss have been compared against the laboratory data of flow over the vegetated dikes.

\section{THEORETICAL FRAME WORK}

Yalin (1964) and Engelund (1966) assumed that the effect of bed forms on the flow is analogous to a sudden expansion in a pipe flow. The Energy loss due to a sudden pipe flow expansion is determined by applying the one dimensional momentum and energy conservation equations over the expansion region. Karim (1999) and Van der Mark (2009) considered the effects of bed form on flow as sudden expansion for free surface flow rather than a pipe flow.

To determine flow velocity and water depth around the weir-like structures such as a submerged groyne or spur dike, following assumptions can be made.

1. Energy is conserved over the upstream face of the groyne or spur dike

2. Momentum is conserved over the downstream side of the groyne.

On the upstream side the streamlines are contracting, energy is conserved there and on the downstream side, there is a sudden expansion so due to expansion loss, energy conservation is not possible. The flow is considered subcritical which happens mostly during the high water stages.

For the upstream side of the groyne, the depth average energy conservation has been applied with assumptions; the flow is steady, frictionless and incompressible. The Pressure is assumed to be the hydrostatic.

\subsection{Case-1 Groyne}

If the obstacle is only the groyne, the depth averaged velocities can be written as,

$u_{0}=\frac{q}{d_{0}} \quad u_{1}=\frac{q}{d_{1}} \quad u_{2}=\frac{q}{d_{2}}$

Here $\mathrm{d}_{0}, \mathrm{~d}_{1}, \mathrm{~d}_{2}$ are water depths and $\mathrm{u}_{0}, \mathrm{u}_{1}, \mathrm{u}_{2}$ are average velocities at sections $0,1,2$ respec- tively as shown in figure 1. $\mathrm{q}$ is the specific discharge. So the respective energy and momentum equations take the following form.

$$
\begin{aligned}
& d_{0}+\frac{\alpha_{0} q^{2}}{2 g d_{0}^{2}}=\Delta+d_{1}+\frac{\alpha_{1} q^{2}}{2 g d_{1}^{2}} \\
& \frac{1}{2} \rho g\left(\Delta+d_{1}\right)^{2}+\rho \frac{\beta_{1} q^{2}}{d_{1}}=\frac{1}{2} \rho g d_{2}^{2}+\rho \frac{\beta_{2} q^{2}}{d_{2}}
\end{aligned}
$$

$\alpha$ 's and $\beta$ 's are energy and momentum correction coefficients for the respective cross sections.

$$
\alpha=\frac{\int V^{3} d A}{V_{m}^{3} \int d A} \quad \beta=\frac{\int V^{2} d A}{V_{m}^{2} \int d A}
$$

Here $V_{m}$ is the mean velocity over the cross section. The additional head loss due to bed friction and flume walls is calculated by the following formulae,

$\Delta H_{b e d}=c_{f} \frac{L u^{2}}{g d}, \Delta H_{w f}=c_{f} \frac{L u^{2}}{g W}$

Here $\Delta \mathrm{H}_{\text {bed }}$ and $\Delta \mathrm{H}_{\mathrm{wf}}$ are energy head loss due to bed friction and wall friction respectively. $\mathrm{L}$ is the length between the flume section 0 and $2 . \mathrm{W}$ is the flume width. cf (Friction coefficient, 0.002 for finished surface) is calculated as follows.

$c_{f}=\frac{g}{C^{2}}$

The Chézy coefficient $C=18 \log \left(12 d / k_{s}\right)$. Here $\mathrm{d}$ is water depth and $k_{s}$ is roughness height.

\subsection{Case-2 Groynes with Vegetation}

\subsubsection{Emerged vegetation}

Energy dissipation in this situation is due to the wake of the weir and the wake behind the cylinders. There probably is an interaction between the wake turbulence generated by the weir and by the cylinders and also between the wake regions of the cylinders but here these interactions have been ignored and only the depth averaged velocity distribution is considered. The effect of vegetation on the cross sectional area is considered and the depth averaged velocity is calculated at this section with reduced cross sectional area due to section contraction and bed rise (weir effect and vegetation cross sectional contraction). In this case the groyne has a row of cylindrical rods on the top of weir crest, these vegetation elements are considered emerged. The velocities at the three cross sections could be written as 


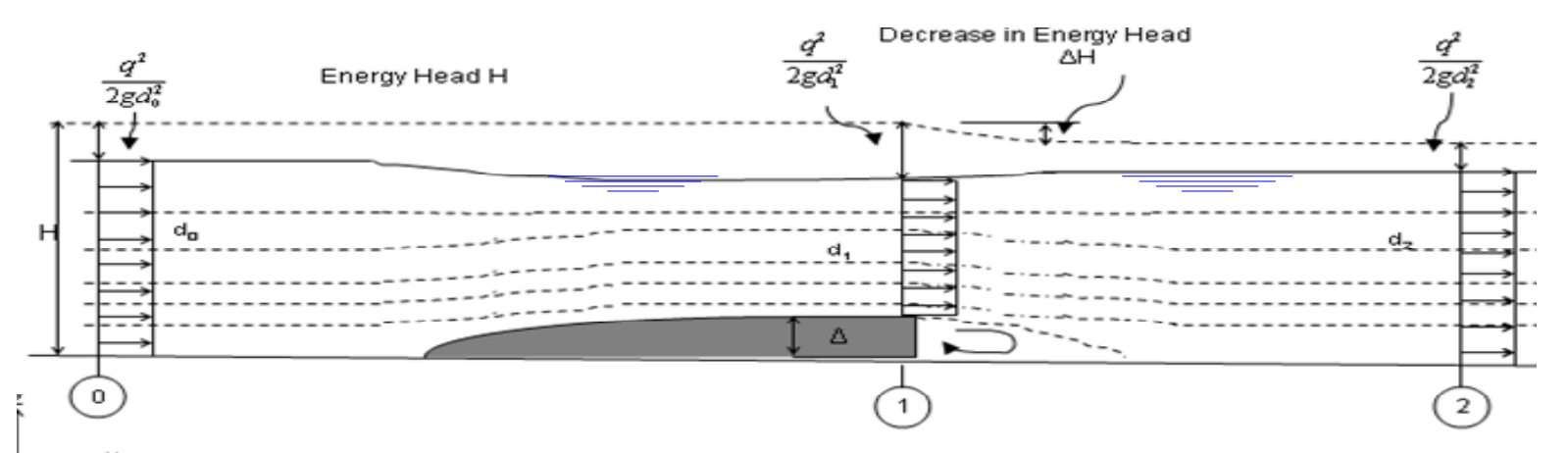

Figure 1. Definition sketch of the free surface flow over a weir.

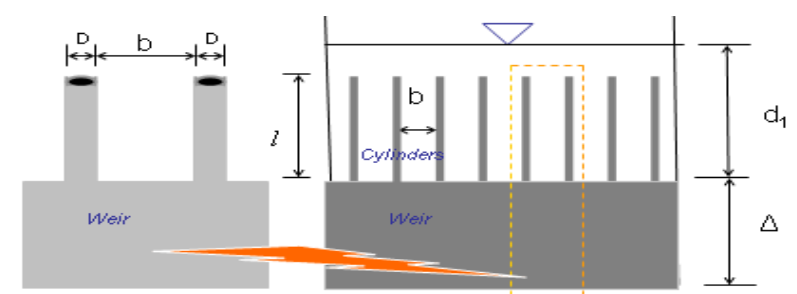

Figure 2. (a) Cross section of vegetated weir at section1.

$u_{0}=\frac{q}{d_{0}}, u_{1}=\frac{q(b+D)}{\left(d_{1} b\right)}=\frac{4 q}{3 d_{1}}, u_{2}=\frac{q}{d_{2}}$,

Here $b$ is the clear distance between two adjacent cylinders and $\mathrm{D}$ is the diameter of a cylinder. The spacing $\mathrm{b}$ is $3 * \mathrm{D}$ producing a $25 \%$ blockage. (Energy conservation)

$d_{0}+\frac{\alpha_{0} q^{2}}{2 g d_{0}^{2}}=\Delta+d_{1}+\frac{16 \alpha_{1} q^{2}}{2\left(9 g d_{1}^{2}\right)}$

Here $\Delta$ is the crest height of the weir. (Momentum conservation)

$\frac{1}{2} \rho g\left(\Delta+d_{1}\right)^{2}+\rho \frac{4 \beta_{1} q^{2}}{3 d_{1}}=\frac{1}{2} \rho g d_{2}^{2}+\rho \frac{\beta_{2} q^{2}}{d_{2}}$

\subsubsection{Submerged vegetation}

For the submerged case (Figure 2), the energy loss is due to the wake of the weir, the wake behind the cylinders and also due to the shear turbulence above the vegetation. There can be a large difference in flow velocities between the vegetated region and overlying region. There are also the interactions between these different turbulent regions. Here these interactions have been ignored and the form drag due to the combined effect of the weir and the vegetation is determined. The depth averaged velocity distribution has been assumed. In this case the vegetation on the weir crest are submerged. Energy and momentum balance upstream and downstream of the weir with the velocities in the 3 cross-sections can be expressed as

$$
u_{0}=\frac{q}{d_{0}} \quad u_{2}=\frac{q}{d_{2}}
$$

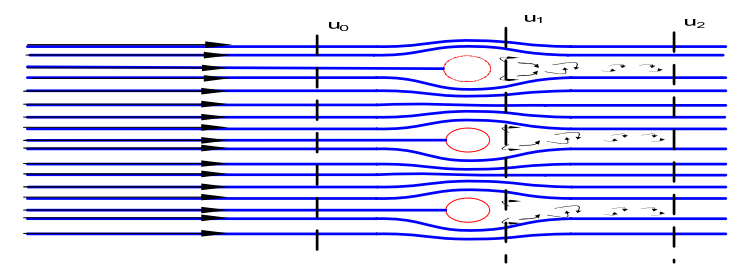

Figure 2. (b) Flow around the pseudo vegetation on the weir crest.

$u_{1}=\frac{q(b+D)}{\left(\left(d_{1}-l\right)(b+D)+l b\right)}=\frac{q}{\left(\left(d_{1}-l\right)+l b /(b+D)\right)}$

$u_{1}=\frac{q}{\left(d_{1}-l+3 l / 4\right)}=\frac{q}{\left(d_{1}-l / 4\right)}$

Here $l$ is the vegetation length

(Energy conservation)

$d_{0}+\frac{\alpha_{0} q^{2}}{2 g d_{0}^{2}}=\Delta+d_{1}+\frac{\alpha_{1} q^{2}}{2 g\left(d_{1}-l / 4\right)^{2}}$

(Momentum conservation)

$\frac{1}{2} \rho g\left(\Delta+d_{1}\right)^{2}+\rho \frac{\beta_{1} q^{2}}{\left(d_{1}-l / 4\right)}=\frac{1}{2} \rho g d_{2}^{2}+\rho \frac{\beta_{2} q^{2}}{d_{2}}$

The energy head loss $\left(\Delta \mathrm{H}_{0,2}\right)$ can be calculated as follows.

$\Delta H_{0,2}=d_{0}+\frac{q^{2}}{2 g d_{0}^{2}}-d_{2}-\frac{q^{2}}{2 g d_{2}^{2}}$ 


\section{EXPERIMENTS}

In order to perform experiments those are representative for the processes on a prototype scale, requirements regarding Froude number and Reynolds number have to be fulfilled. To this end the prototype conditions are schematized and down scaled approximately 1:50, doing so a Froude number scaling is achieved. The low Reynolds number is not considered a problem as long as the flow is fully turbulent. The Reynolds number is of order $10^{4}$. Selected discharges for different setups are $0.02,0.025,0.03,0.035,0.04,0.045,0.05$,

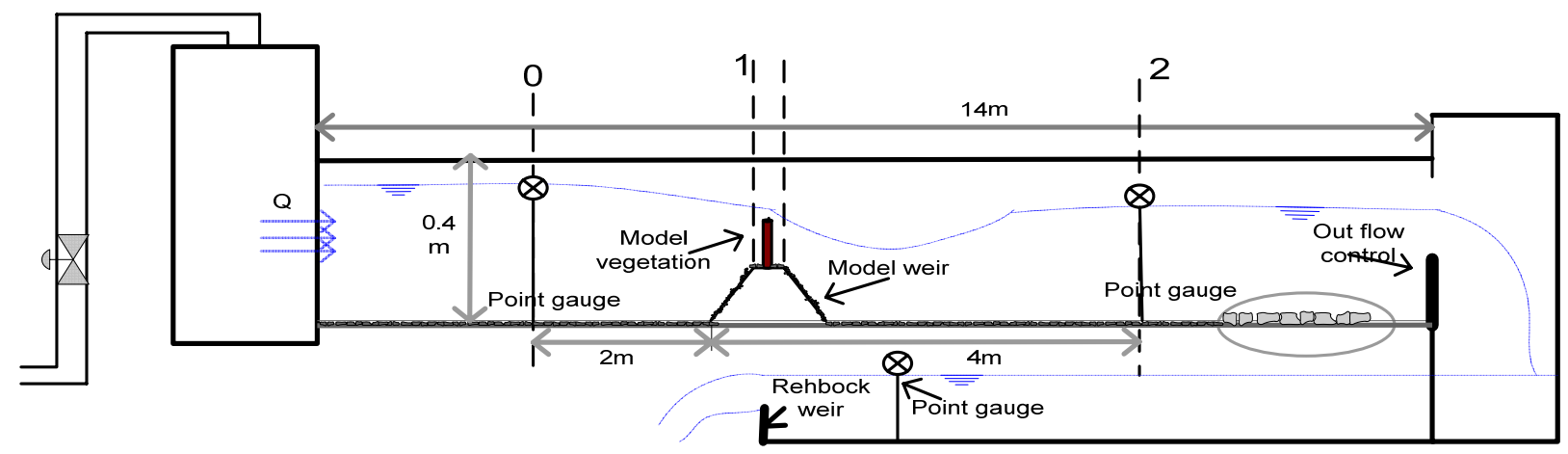

Figure 3.Experimental rectangular flume.

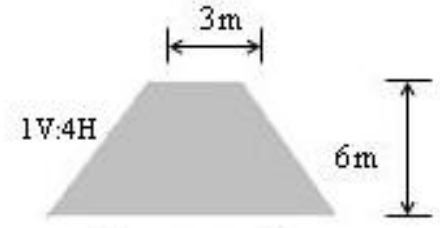

Prototype dike

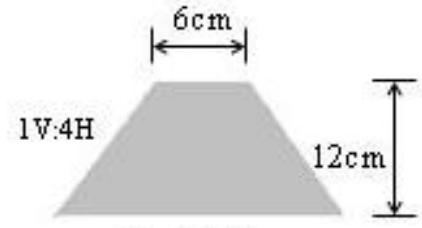

Model dike

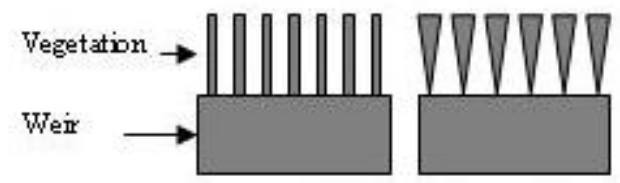

Frontal views of vegetated weir

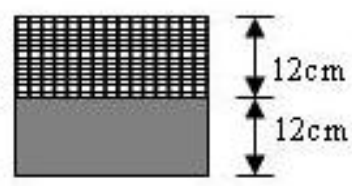

Side view of vegetated weir

Figure 4. Prototype Dike and Model weir (scaled 1:50).

$0.06 \mathrm{~m}^{3} / \mathrm{sec}$. A $14 \mathrm{~m}$ long glass flume (Figure 3) was used for tests. The Flume was rectangular 0.4 $\mathrm{m}$ wide and $0.4 \mathrm{~m}$ deep. To control the downstream water level a vertical gate was placed at the downstream end of the flume. The discharge to the flume was regulated by means of a valve and measured by using a calibrated Rehbock weir in the return section. The flume bed as well as the weir has been made hydraulically rough by gluing $5 \mathrm{~mm}$ to $8 \mathrm{~mm}$ diameter gravel to the bed to represent the actual field conditions as in the floodplain.

For this study a trapezoidal dike shape is used. It has a height of $6 \mathrm{~m}$, crest width of $3 \mathrm{~m}$ and a side slope of $1 \mathrm{~V}: 4 \mathrm{H}$ on the upstream side and $1 \mathrm{~V}: 4 \mathrm{H}, 1 \mathrm{~V}: 7 \mathrm{H}, 1 \mathrm{~V}: 15 \mathrm{H}$ downstream. The model of the prototype (Figure 4) is made of polished wood on a scale of $1 / 50$. So the model weir has a height of $12 \mathrm{~cm}$ and a crest width of $6 \mathrm{~cm}$. The side slopes of the model weir were the same as with the prototype. The surface was made hydraulically rough by gluing gravels to it. The vegetation on the weir crest is modeled by using circular cy- linders, cones and gaze with mesh sizes $5 \mathrm{~mm}$ and $10 \mathrm{~mm}$. The Blockage area on the top of the weir due to the model vegetation is $25 \%$ (in side the vegetated region). The Height of all plants is equivalent to the weir crest height $(12 \mathrm{~cm})$. On the top of flume point gages were installed to measure the water level at section $0,2 \mathrm{~m}$ upstream of the weir, section 1 at the crest of weir (upstream and downstream of the vegetation) and section 2, $4 \mathrm{~m}$ downstream of the weir with an accuracy of 0.1 mm. A Laser Doppler velocimeter has been used to measure the velocity profiles at different locations around the vegetated weir.

\section{RESULTS AND DISCUSSION}

\subsection{The Skin resistance compared with the form resistance of the weir}

Figure 5 is showing the comparison of energy head loss due to the rough bed ( $k_{s}$ is $\left.6 \mathrm{~mm}\right)$ with- 
out the weir and with the weir of down stream slopes 1:4 and 1:7. It could be seen from this graph that the energy head loss due to the bed roughness is almost $50 \%$ of the energy head loss with the weir (down stream slope 1:4). The energy head loss due to the weir with a down stream slope $1: 7$ is $25 \%$ less than the weir with a down stream slope 1:4. The weir with a less steep downstream slope has a smaller separation zone resulting in less energy head loss. In these measurements the skin friction has a substantial contribution to the total energy head loss so this contribution can not be ignored when analyzing the results.

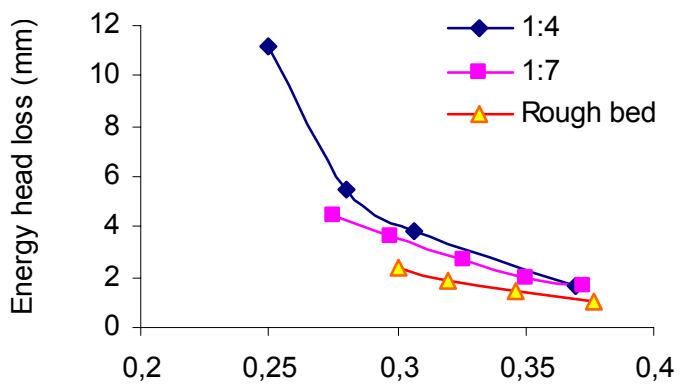

Dow $n$ stream w ater depth $(m)$

Figure 5. Comparison of energy head loss due to the bed roughness and different weir configurations $(Q=301 / \mathrm{sec}$, Down stream slope 1:4 and 1:7).

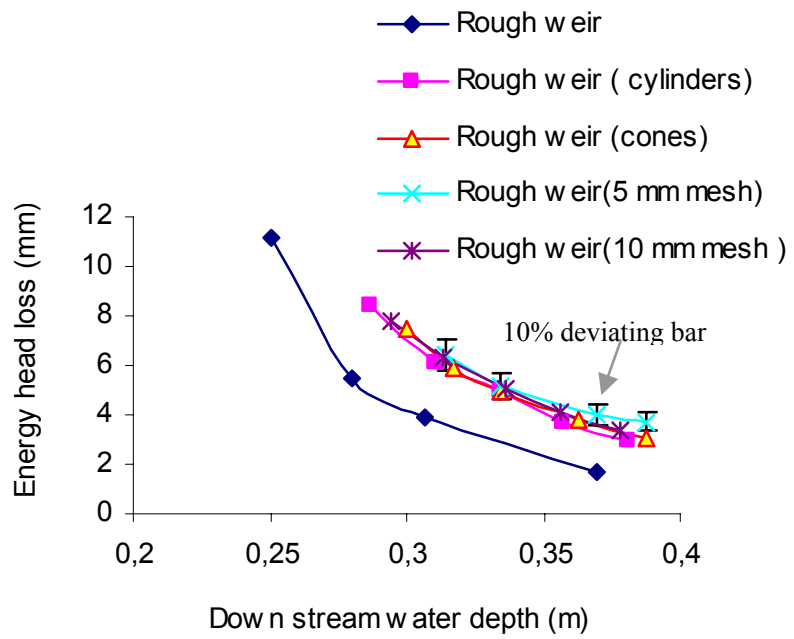

Figure 6. Comparison of energy head for different types of vegetation on weir crest $(\mathrm{Q}=30 \mathrm{l} / \mathrm{sec}$, Down stream slope $1: 4)$.

\subsection{Comparison of head loss for different types of pseudo vegetation on the weir}

Figure 6 shows the comparison of the energy head loss due to the vegetated weir with different vegetation shapes. Though the differences are small, it is clear from this graph that maximum energy head loss is due to the gaze with mesh size $5 \mathrm{~mm}$ and the minimum energy head loss is due to the cylinders. The energy head loss due to the gaze is more because the more turbulence is produced at a small scale resulting in a more dissipation. Perhaps the vertical non-uniformity results in enhanced turbulence. Here in the figure 6 , the $10 \%$ deviation bars with respect to the energy head loss due to the gaze with a mesh size $5 \mathrm{~mm}$, are shown. It can be concluded that the energy head loss due to the different shapes of vegetation is varying within $10 \%$. So the effect of the shapes of vegetation is not more than $10 \%$, where as the vegetation itself causes up to a doubling of the losses.

\subsection{Measured vertical profiles of longitudinal velocity around a vegetated weir}

Figure 7 shows the vertical profile of horizontal velocity at different cross sections around the weir for down stream slope 1:4 and with a discharge $Q$ $=40 \mathrm{l} / \mathrm{sec}$, the downstream water depth is $0.34 \mathrm{~m}$. The vegetation on the crest of the weir is submerged. The values for $\alpha_{1}$ and $\beta_{1}$ are calculated from the measured velocity profiles behind the vegetation on the crest of the weir according to equation (4) and are found to be 1.18 and 1.03 respectively. The velocity profile becomes again logarithmic behind the weir at a distance $1.5 \mathrm{~m}$ downstream from the crest of the weir for the case without vegetation. This distance is about 12.6 times the weir height. In case of the vegetated weir this distance is $2 \mathrm{~m}$ from the crest of the weir. It is about the 16.7 times the crest height. If we would raise the crest height corresponding to the blockage area of the vegetation, then the effective crest height is $0.15 \mathrm{~cm}$ and the distance at which we got the logarithmic profile again is 13.3 times the effective weir height. So we can see the effect of vegetation here causing a wake which delays the recovery of the logarithmic profile.

\subsection{Analysis of energy head loss using expansion loss form drag model}

The expansion loss form drag model was applied to analyze the form drag of the vegetated weir. Due to the contraction in flow, velocity is increased, after the contraction, there is the sudden expansion resulting in a decelerating region. So the energy head loss is established in this expan- 
sion region. In case of the weir with the down stream slope 1:4, large separation zone is at the downstream side and in this separation zone, the turbulence is generated. But for the case of a weir with a down stream slope 1:7, the separation zone is small, and sometimes absent. Due to this reason the energy head loss is less in comparison with the sudden expansion. To calculate the head loss due to a gentle down stream slope we apply the mo- mentum balance on the down stream side in two steps. Doing so, the energy head loss predicted by the model is comparable to the measured head loss. In case of the submerged vegetation, there is a shear layer due to the velocity difference through the vegetation and the upper flow layer. This shear layer is also contributing to the energy loss. To compensate for this effect we are using the kinetic energy and the momentum correction factor $(\alpha$,

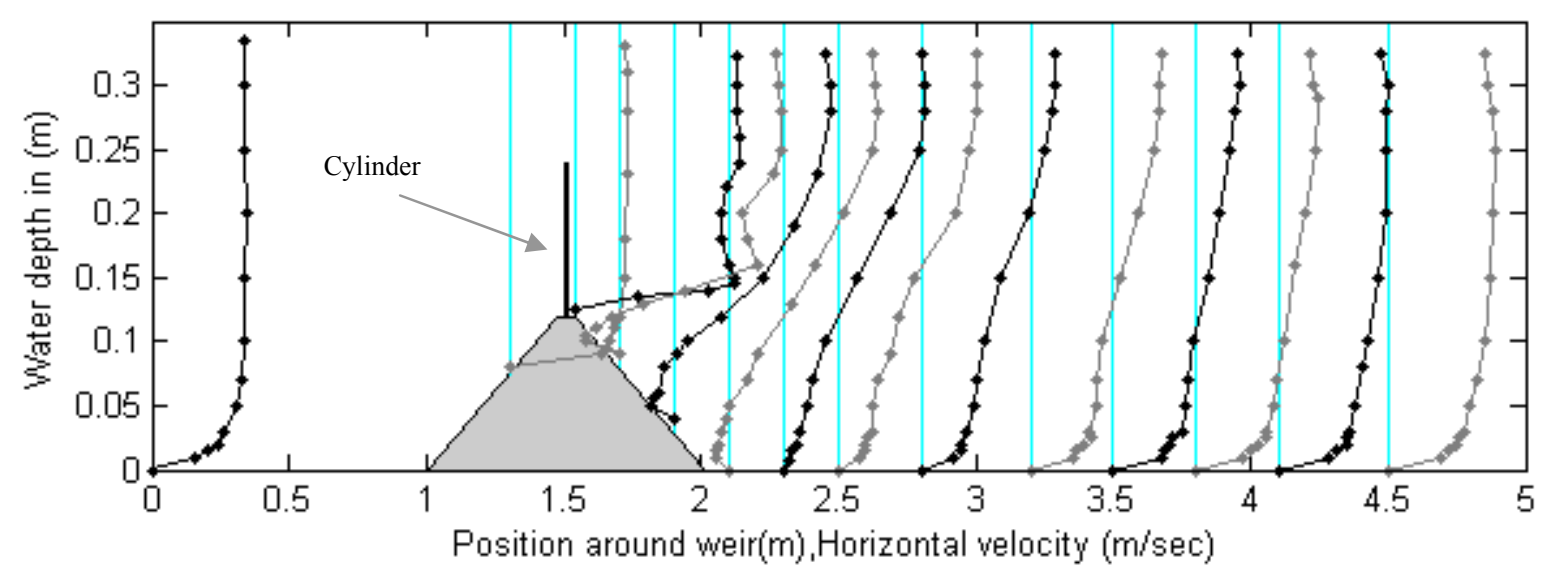

Figure 7. Measured Horizontal velocity profiles for rough weir (with cylinders) with downstream slope of weir 1:4 (Submerged flow conditions, Froude No. at the crest of weir is 0.34$) \mathrm{Q}=40 \mathrm{l} / \mathrm{sec}$.

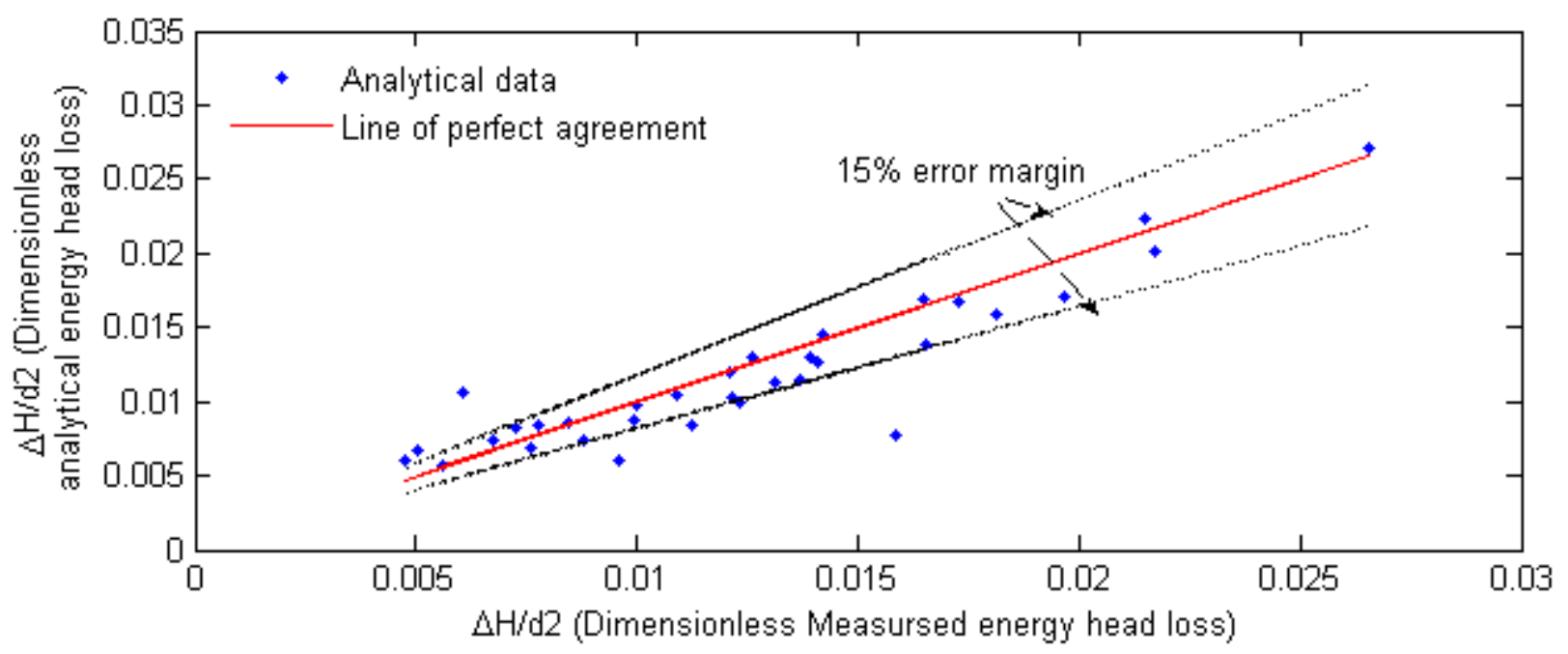

Figure 8 . Energy head loss predicted by the expansion loss form drag model versus experimental results. (Along x-axis- experimental data and along $\mathrm{y}$-axis predicted results). (Vegetated weir (cylinders) downstream slope of weir 1:4).

$\beta$ ). These coefficients are needed to take into account the effect of the non-uniform velocity distribution. We are using here $\alpha_{1}=1.18$ and $\beta_{1}=1.03$ (Chaudry, M.H.1994). Figure 8 is showing the comparison of the predicted and the experimental results. The expansion loss form drag model can predict the energy head loss within $15 \%$. Some points are deviating more; these are for Froude number more than 0.4 at the weir crest in side the vegetation.

\section{CONCLUSIONS}

It is found that the vegetation on the crest of the weir give rise to a substantial increase in energy head loss. The shapes of vegetation do matter but the difference in head loss due to different vegetation shapes is small. Also it is found that the gaze with mesh size $5 \mathrm{~mm}$ on the crest of the weir cause more resistance than others shapes like cylinders, and cones but this effect is within $10 \%$ of 
the total energy head loss. It is obvious from the experimental results that the flow resistance due to the weir-like structure with the gentle downstream slope is less than steep slope.

The energy head loss predicted by the expansion loss form drag model has been compared with the experiments for the submerged vegetated weirs. The expansion loss form drag model appears to provide a good basis for the prediction of the energy head loss for submerged and subcritical flow conditions. In case of submerged vegetation, due to difference in flow velocities in the vegetated and the surface layer, the velocity correction factors are needed. When the Froude number is 0.4 or more above the crest of weir, the flow starts undulating on the downstream slope of the weir. It is due to the slope, as on the slope the flow accelerates, it becomes critical and the flow surface starts to undulate. In this case predictions by the expansion loss form drag model deviate from measured values due to the non- hydrostatic pressure distribution. So this model is applicable for submerged and subcritical flow conditions only.

\section{ACKNOWLEDGMENTS}

Authors would like to acknowledge the Higher Education Commission of Pakistan (HEC), Ministry of Transport, Public works and water management (RWS), the Netherlands and Deltares Delft, the Netherlands, for their contribution to this research project.

\section{REFERENCES}

Abou-Seida, M. M., Quraishi, A.A. 1976. A flow equation for submerged rectangular weirs. Proc. inst. Civil Eng., 61, No.2, 685-696.

Azinfar, H., Kells, J.A. 2009. Flow resistance due to a single spur dike in an open channel. Journal of Hydraulic research, pp.755-763.

Baptist, M.J. 2005. Modeling floodplain biogeomorphology. Delft University Press, Delft.

Chanson, H. 1999. The hydraulics of open channel flow. John Willey \& Sons Inc.

Chaudhry, M.H.1994. Open Channel flow. Prentice-Hall International.

Chow, V. T. 1959. Open channel hydraulics. McGraw-Hill, Tokyo.

Engelund, F. 1966. Hydraulic resistance of alluvial streams. J.Hydr. Eng. Div., 92 (HY2), 315-326.

Govida Rao, N.S., Muralidhar, D.1963. Discharge characteristics of Weirs of finite crest length. La Houille Blanche, 5,537-545.

Henderson, F.M.1966. Open channel flow. The Mac-millan Company, New York.

Jain, S.C.2001. Open channel flow, John Wiley and Sons, New York.
Järvelä, J. 2004. Determination of flow resistance caused by non-submerged woody vegetation. Journal of river Basin Management 2 (1), 61-70.

Karim, F.1999. Bed-form geometry in sand bed-flows. J. Hydraulic Eng.,125(2), 1253-1261.

Kouwen, N., Fathi-Moghadam, M. 2000. Friction factors for coniferous trees along rivers. Journal of Hydraulic Engineering 126(10), 732-740.

Kouwen, N., Unny, T.E. 1973. Flexible roughness in open channels. Journal of the Hydraulics division HY5,713728.

Lakshamana Rao, N.S. 1975.Teory of weirs, Advances in hydroscience,Vol. 10. Academic press, Inc., New York, pp 310 - 406.

Li, R.M., Shen, H.W. 1973. Effect of tall vegetations on flow and sediment. 99(HY5), pp.793- 814.

López, F., García, M.H. 2001. Mean flow and turbulence structure of open channel flow through non-emergent vegetation. Journalof Hydraulic engineering 127 (5), 392-402.

Nepf, H. M. 1999. Drag, Turbulence and diffusion in flow through emergent vegetation. Water Resources Research, 35(2), 479-489.

Rehbock,T. 1929. Discussion of precise weir measurements. Trans., ASCE, 93, 1143-1162.

Swamee, P.K. 1988. Generalized Rectangular Weir equations. JHE, ASCE, 14, no.8, 945-949.

Van der Mark, C.F. 2009. A Semi-Analytical Model for form drag of river bed forms. University of Twente, the Netherlands.

Villemonte, J.R.1947. Submerged Weir Discharge Studies. Eng. News Record, 193, 866-869.

Yalin, M.S.1964. On the average velocity of flow over a mobile bed. La Houille Blanche, 1, 45-53.

Yossef, M. F. M. 2005. Morphodynamics of rivers with groynes. Delft University Press, Delft. 